\title{
Cortico-hippocampal interplay: Self-organizing phase-locked loops for indexing memory
}

\author{
ROBERT MILLER \\ University of Otago Medical School, Dunedin, New Zealand
}

\begin{abstract}
A difficulty with the connectionist idea of representation in neural networks of the mammalian brain is that a single neuron cannot make a sufficient number of connections to influence the functional organization within networks of realistic size. Although cell assemblies can form to represent individual stimuli and responses, the formation of assemblies capable of recognizing an environment as a whole is unlikely. Yet such recognition is necessary for many contextdependent types of behavior. In the present paper, a hypothesis of cortico-hippocampal interaction is suggested, which can resolve this difficulty. It involves the establishing of patterns of connectivity between the cortex and hippocampus, on the basis of temporal aspects of connectivity (i.e., axonal conduction delays) as well as spatial aspects. By means of both the available repertoire of axonal conduction delays and Hebbian processes for synaptic modification, loops of connectivity are selected which carry neural activity resonating at the frequency of the hippocampal theta rhythm. Patterns of such loops encode the environment as a whole. The relation between the hippocampal theta rhythm and both general behavior and learning processes is thus clarified.
\end{abstract}

It is generally believed that acquired information is stored in the brain, especially in its cortices, in patterns of modified connections. The connections may be strengthened or weakened during learning, and thus they can build up a picture of associations and patterns inherent in the learning situation. The paradigm put forward by Hebb (1949) for such synaptic modification is now supported by a considerable body of evidence (Goddard, 1980; Smith, 1987; Wickens, 1988; Wigström \& Gustafsson, 1985). Other paradigms of synaptic modification may apply in structures other than the cerebral cortex and the hippocampus (Brindley, 1967; Ito, 1986; Miller, 1981, 1988; Stent, 1973). However, there is a difficulty in this picture of learning, because typical neurons have many thousands of input and output connections, so that neural networks allow an immense convergence and divergence of signals. Even if the representation of learned information is based on connections, it is difficult to see how this representation can be specific.

It has also been argued that the information-storage capacity of the brain is so great that the unit of information storage must be the individual synapse and not the neuron itself (Palm, 1980, 1982). Only in this way can nervous tissue store information with adequate economy. If

I thank Jeff Wickens for many discussions of concepts, presentation, and terminology. I also thank Valentino Braitenberg and Gunther Palm for discussions at an early stage, Robin Harvey for helpful comments on an early draft, and Robbie McPhee for producing the diagrams. This work is supported by the Neurological Foundation of New Zealand. Correspondence should be addressed to Robert Miller, Department of Anatomy, and Neuroscience Centre, University of Otago Medical School, P.O. Box 913, Dunedin, New Zealand. this is true, a single neuron must participate in the representation of many different associations, acquired in different circumstances. A plausible scheme or principle for such storage, sometimes called the "correlation matrix," has therefore been advanced by several authors (Kohonen, 1977; Marr, 1969; McNaughton \& Morris, 1987; Palm, 1980). Such a matrix involves Hebb-like synapses in producing a distributed pattern of information storage in neural networks (that is, the representation of each concept or event is spread over a large number of neurons). This scheme reconciles the two conflicting design constraints defined above-the specificity and the economy of information storage.

Cortical tissue contains many local (intrinsic) connections. If these connections were also of Hebbian type, the cells that collectively represent a concept or event would organize themselves into a "cell assembly" (Braitenberg, 1977; Hebb, 1949; Palm, 1980, 1982). (For reasons soon to become apparent, this collection will be called here a "local cell assembly.") In this collection, the firing of any member of the group would partly depend on that of other members of the group. The disadvantage of this assumption is that the greater the mutual dependence of neuronal firing of members on each other, the less efficient would be the information storage by each neuron.

There is a third design constraint that must be considered too: Although each neuron has many thousands of connections with other nerve cells, this is still a relatively limited number of connections for some purposes. It will be argued below that for information processing that requires the associative potential of the cortex as a whole, this limit may prevent the correlation matrix principle from functioning adequately with respect to the first two design constraints. 


\section{The Need for "Global Cell Assemblies"}

Consider the information structure of the environment. The important categories for the brain are not single stimuli or responses ("items"), as envisaged in the tradition of stimulus-response learning theory. Rather, they are abstractions or generalizations from many stimuli or responses. One may designate these "Gestalts" (Kohler, 1938) as "objects" or "response intentions." The representation of Gestalts through coordination of the representation of items could easily come about by operation of the Hebbian principle, acting on intrinsic cortical connections: Small cell assemblies could "coalesce" into a larger one, if their activations tended to be correlated.

In addition, the information structure of the environment may contain ambiguities. A single stimulus may be a part of several objects, so that a single stimulus occurring in isolation may be inherently ambiguous. Likewise, an object considered in isolation may be ambiguous, since it may be a potential trigger for a variety of different responses, each appropriate in different circumstances. These ambiguities, which apply to "items" of information, can often be resolved in practice, if the totality of the environment is brought to bear on the representation of the "items." However, although it is clear that environmental ambiguity is often resolved in this way, surprising difficulties appear when one tries to explain how.

The obvious first answer to the resolution of this environmental ambiguity is again the correlation matrix principle. In such a matrix, if a big enough fraction of the information belonging to a pattern were to be presented, that pattern could be uniquely identified, even when data is incomplete. For example, the ambiguity of a single image of an object could be resolved if several images of the same object were presented (and represented) concurrently. As an extension of this principle, it is possible that in the ambiguous situation of a single image presented in isolation, or of an object that could trigger a variety of responses, the ambiguity could also be resolved if the whole environment in which these patterns habitually occur were also represented. In other words, to resolve the ambiguity of a single image or object, the representation of that image or object would have to be addressable to its particular "global cell assembly," representing just the environment in which that image or object could occur.

\section{The Effect of the Size of the Network}

It is reasonable to expect that the cortex required to represent the environment as a whole must be larger than that necessary to represent only specific stimuli and responses. However, as the size of the cortex increases, the proportion of appropriately connected neurons in the cortex must fall dramatically.

Imagine a block of cortical tissue $A$, containing $N$ principal neurons, with an input from another part of the cortex such that each afferent neuron distributes $n$ connections in $A$. Then the probability $\left(P_{s}\right)$ of a neuron in $A$ 's receiving a single connection from a particular afferent neuron is given by Equation 1:

$$
P_{s}=\frac{n}{N}
$$

Following Palm $(1980,1982)$, the approximate information capacity of an average neuron in a well-filled correlation matrix $\left(C_{s}\right)$ is that shown in Equation 2:

$$
C_{s} \bumpeq 0.7 \cdot n \text { bits }
$$

-assuming that a single synapse corresponds to one bit of storage capacity. Suppose that the region of afferent cortex contains cell assemblies in which the firing of one member may determine that of others. Suppose also that, on the average, the firing of a single neuron determines the firing of $k$ other neurons. The probability $\left(P_{k}\right)$ of at least one member of such a mutually dependent assembly's sending a connection to a particular neuron in $A$ is given in Equation 3:

$$
P_{k}=\frac{n k}{N} .
$$

However, since the afferents from members of a cell assembly fire in mutual dependence, the information capacity of the connections from the cell assembly to the neuron in $A$ would not change from that in Equation 2. If it requires the convergence of $t$ active afferents on a single neuron to bring it to the threshold for firing, the probability $\left(P_{c}\right)$ of a neuron in $A$ 's being appropriately connected so that it will fire to the concurrent activation of a selection of $t$ afferents is given in Equation 4 (assuming random connectivity):

$$
P_{c}=\left(\frac{n k}{N}\right)^{t} \text {. }
$$

The precise value of $t$ is uncertain. However, a slightly arbitrary yet plausible inference can be made from the data of Creutzfeldt and Ito (1968) and Creutzfeldt, Maekawa, and Hosli (1969). Their findings suggest that a unitary EPSP in a cortical pyramidal cell has an amplitude of $0.5-3 \mathrm{mV}$, whereas depolarization to the threshold for firing requires 5-10 $\mathrm{mV}$ depolarization. On the basis of these data, $t$ is given a value of 3 . This is probably an underestimate, and it is deliberately so, in order to guard against error in the conclusion derived below.

In Equation 4 , as $N$ becomes much larger than $n$, the probability $\boldsymbol{P}_{c}$ will decline sharply until it is unlikely that there will be even one appropriately connected neuron in the whole block. For instance, if $N=10^{5}$ (as in a block of tissue about $1 \mathrm{~mm}^{3}$ ), and $n=10^{4}$,

$$
P_{c}=\frac{k^{3}}{1,000} \text {. }
$$

If $N=10^{8}$ (as in a block of tissue about $1 \mathrm{~cm}^{3}$ ), the other assumptions remaining unchanged,

$$
P_{c}=\frac{k^{3}}{10^{12}},
$$

which is equivalent to a very small absolute number of neurons. It is difficult to estimate $k$. However, the following conclusion that emerges from this analysis is clear: 
As the sizes of the mutually dependent groups of neurons increase, so the proportion of appropriately connected neurons increases. But the amount of information that can be stored in the block of neurons by these connections stays the same. Thus, if one postulates that the correlation matrix principle forms a global cell assembly that can resolve the ambiguity of a small portion of the environment, one is caught on the horns of a dilemma: With cell assemblies of small size, there are too few connections to form the global cell assembly. With larger cell assemblies, there are enough connections, but the global cell assemblies so formed still contain insufficient information to adequately represent the environment as a whole.

The hypothesis presented below is an attempt to resolve this dilemma. One of the principles on which it is founded is that axonal connections encode not only the linking of two neurons, but also a temporal relation between their firing (Miller, 1987). Then, since an axon may be able to recruit the Hebbian mechanism by virtue of the temporal as well as the spatial aspects of its connection, the limit on connectivity will not be as severe as at first appears. Given this principle, it can be proposed that the cerebral neocortex and the hippocampus are able to organize their mutual connectivity into patterns of resonating loops, entrained to the hippocampal theta rhythm. Each such pattern of resonating loops is envisaged as encoding a particular environment. Such a pattern of resonance thus activates a particular global cell assembly in the neocortex, consisting of cells that are too weakly interconnected to form themselves into a group by means of the processes that are usually envisaged as setting up cell assemblies.

\section{Connectivity between the Neocortex and the Hippocampus}

One aspect of the connectivity from the cortex to limbic structures such as the hippocampus is that it constitutes the most powerful multimodal convergence within any forebrain structure (with the exception of language zones in the higher primate) (Geschwind, 1965a, 1965b). It is thus appropriate to consider that this converging pathway might play a part in the representation of the environment as a whole. The present hypothesis envisages a dynamic interplay between the neocortex and hippocampus, which implies the existence of abundant reciprocal pathways between them. Earlier neuroanatomical work indicated that such pathways might exist via the diencephalon, the socalled circuit of Papez (Brodal, 1969; Papez, 1937). Recent connectional studies have added evidence for more direct reciprocal links between the two structures, entirely within the telencephalon (Cavada, Llamas, \& ReinosoSuarez, 1983; Goldman-Rakic, Selemon, \& Schwartz, 1984; Insausti, Amaral, \& Cowan, 1987; Irle \& Markowitsch, 1982; Meibach \& Siegel, 1977; Rosene \& Van Hoesen, 1977; Schwertfeger, 1979; Van Hoesen \& Pandya, 1975a, 1975b; Van Hoesen, Pandya, \& Butters, 1972). The neocortical region most directly involved in these pathways is the prefrontal cortex, but other regions of the cor- tex (cingulate cortex, parietal and temporal association cortex) are directly involved to a lesser extent, and they are certainly also involved by indirect (polysynaptic) links.

In addition to these "spatial" aspects of connectivity, one must also consider the temporal aspects. It has been argued (Miller, 1987) that cortico-cortical connections, by virtue of their length and fine caliber, act as a spectrum of "delay-lines" : between $20 \%$ and $40 \%$ of corticocortical axons are unmyelinated. Histograms of the caliber of these unmyelinated axons indicate a median diameter of about $0.25 \mu$, the finest axons being under $0.1 \mu$ (Fleischhauer \& Wartenberg, 1967; Remahl \& Hildebrand, 1982; Waxman \& Swadlow, 1976). The conduction velocity for unmyelinated central axons has been estimated as $0.5 \mathrm{~m} / \mathrm{sec}$ for a caliber of $0.5 \mu$ (Lee, Chung, Chung, \& Coggeshall, 1986). The slowest conducting unmyelinated central axons appear to have a conduction velocity of about $0.15 \mathrm{~m} / \mathrm{sec}$ (Ferraya Moyano \& Molina, 1980). Antidromic stimulation studies have shown a proportion of conduction delays for cortico-cortical axons as long as $\mathbf{4 0}$ or $\mathbf{5 0} \mathrm{msec}$ (Miller, 1976; Swadlow, 1974). The latter studies, for technical reasons, have probably underestimated the latency and relative abundance of these very slow conducting axons (Miller, 1987). These conclusions probably apply as much to cortico-hippocampal connections as they do to the other cortico-cortical axons. In the rat, for instance, antidromic responses between the frontal cortex and the hippocampus have been observed with latencies of up to 26 msec (Ferino, Thierry, \& Glowinski, 1987). This study also probably underestimates the conduction delay between the hippocampus and the prefrontal cortex. Thus, given a conduction distance between the hippocampus and the prefrontal cortex (in the rat) of $10-15 \mathrm{~mm}$, and a slowest possible conduction velocity of about $0.15 \mathrm{~m} / \mathrm{sec}$, the longest possible axonal conduction delays may be 60-100 msec.

Figure 1 presents a schematic diagram of a loop of axons from the hippocampus to the association cortex and back again (via areas of the prefrontal cortex). In accord with the above rough estimates, it is postulated in the figure that there are a significant number of axonal connections between the hippocampus and the prefrontal cortex in either direction with delays of the order of $50 \mathrm{msec}$. Further connections between the prefrontal and the nonlimbic association cortex (in either direction) are estimated to contribute about $30 \mathrm{msec}$ (in either direction). Delays through the hippocampal circuitry are estimated to contribute about another $\mathbf{4 0} \mathrm{msec}$ (a figure derived from the account of laminar phase profiles in the free-moving rat; see below). Thus, total loop time may approach $200 \mathrm{msec}$ for the slowest conducting axons.

\section{General Statement of the Hypothesis}

It has been proposed elsewhere (Miller, 1987) that the variety of delay lines converging upon single cortical neurons is sufficient to represent temporal patterns spread over a duration of $100 \mathrm{msec}$ or more. Suppose also that these connections are modifiable by Hebbian mechanisms. 


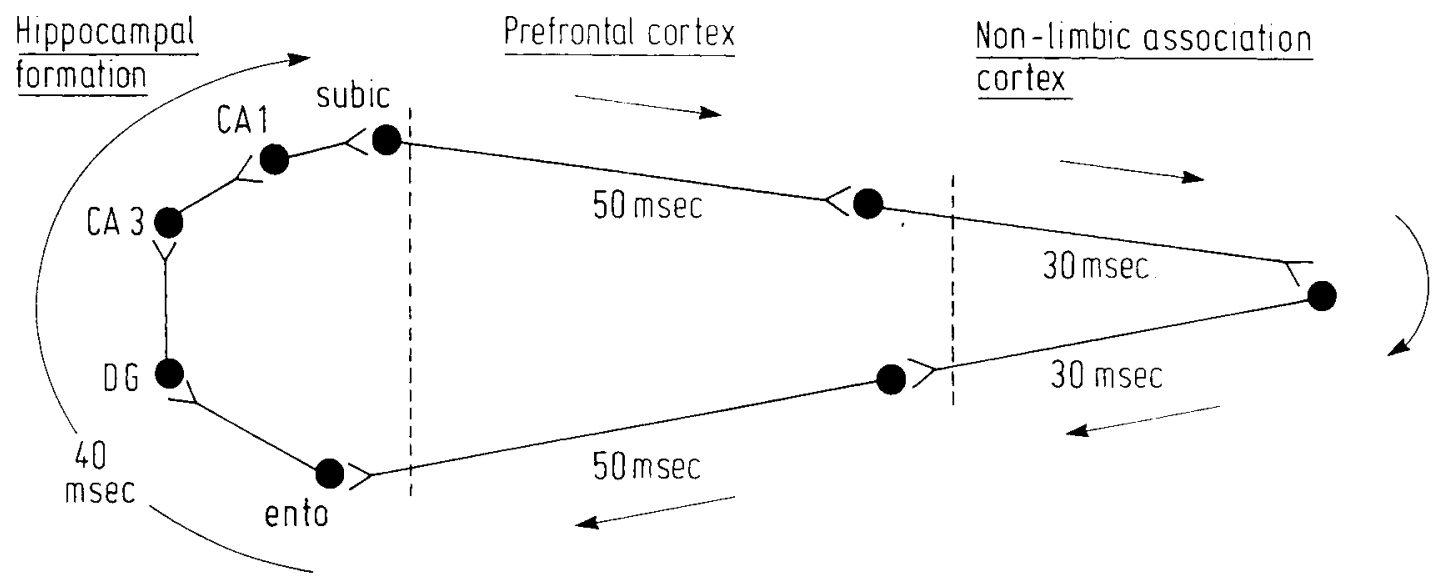

Figure 1. Schematic diagram showing probable longest delay times in loops of axonal pathways between the hippocampus and the association cortex. The 40-msec delay within the hippocampus is derived from data considered in the section "Laminar Profiles of Theta Activity." Maximum loop time may be in excess of 200 msec.

Assume that the Hebbian mechanism has a temporal resolution of about 20 msec (Gustafsson \& Wigström, 1986; Levy \& Steward, 1983); then there will be a physiological as well as an anatomical organization that would allow single neurons to come to represent such brief temporal patterns.

Consider next the situation of two cerebral structures (viz., the neocortex and hippocampus), reciprocally linked by loops, each limb of which consists of such a variety of long delay lines (Figure 2). Suppose a regular cycle of rhythmic neural activity is imposed at one end of such a series of loops. For those axonal pathways with a total loop time that is about the same as the period of the imposed rhythm, signals generated by one beat of the oscillator will return to the oscillator in time for the next beat. This is exactly the circumstance in which the Hebbian mechanism is recruited. If Hebbian mechanisms are supposed to operate at both ends of the loop, the synaptic

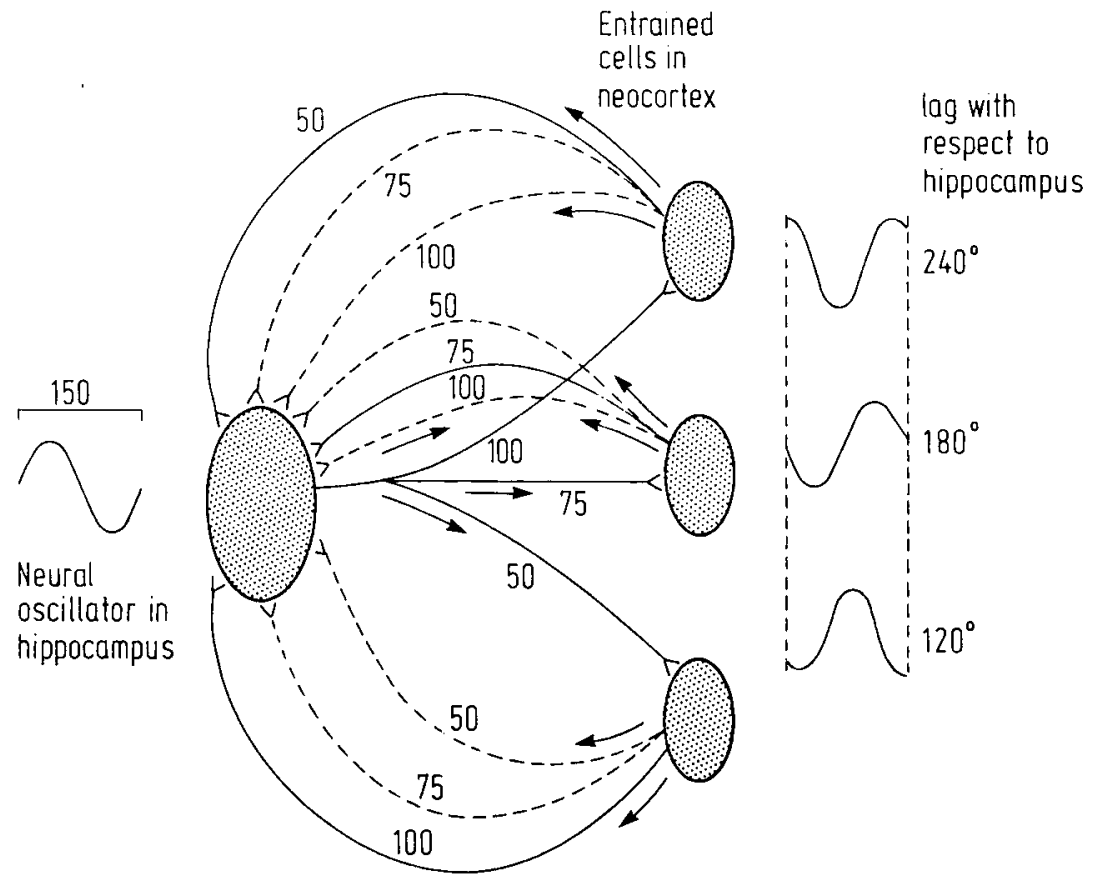

Figure 2. Scheme for self-organization of phase-locked loops. The master oscillator (the hippocampus) has afferent and efferent links with a variety of neocortical loci. All links include lines with a range of delays. Conduction delay, in milliseconds, for each axonal link is shown by numbers adjacent to each axon. Through the strengthening of selected axons with the appropriate delays (solid lines, depicted here as having total loop times of $150 \mathrm{msec}$ ), the neocortical loci can become entrained to the hippocampal rhythm. Different neocortical loci will have different phase relations with the hippocampal rhythm (right). 
modifications that occur will tend to strengthen just those connections which form loops whose delay times approximate the oscillator period. In such a mechanism, selforganization of loops of strengthened connections will occur, whose activity is phase-locked to that of the neural oscillator.

The hippocampus generates the most regular electrographic rhythm in the mammalian brain (the theta rhythm, reviewed below), which has a frequency of 4-12 Hz (period of 83-250 msec) in rats and a somewhat slower frequency in larger-brained animals. All the premises required for self-organization of phase-locked loops between the hippocampus and cortex thus seem to be fulfilled.

\section{Role of Phase-Locked Loops \\ in Cortical Information Processing}

Before the consideration of relevant details of the hippocampal theta rhythm, it is appropriate to spell out more fully how phase-locked loops are envisaged as forming, and how they participate in information processing. For an animal in a particular environment, for example, a collection of widely scattered cortical cells might be set into a state of tonically elevated activity. However, their mutual interconnections would be so weak that they could not organize themselves into a conventional cell assembly representing that environment.

Suppose that the hippocampus is rhythmically active at the same time as these neocortical cells are tonically active. The neocortical neurons could then receive rhythmic signals through connections from the hippocampus, and the synapses of these connections on the cortical neurons would progressively strengthen by means of Hebbian mechanisms. The cortical neurons would then show a rhythmicity, phase-locked to the hippocampal rhythm. Synapses of connections returning to the hippocampus could then be strengthened only if the conduction delay of these connections synchronized approximately to a succeeding beat of the theta rhythm.

In actual practice, it may also be necessary to postulate that the hippocampo-cortical connections have the form of polysynaptic reciprocal networks, rather than the simple loops depicted in Figure 2. For such pathways to participate in the self-organization of phase-locked loops, certain structural and functional properties of local cortical circuits are required: these circuits should transmit to their efferents a rhythm imposed by the afferents, without obliteration by averaging of the several afferent signals that might converge on the local circuit. There is no data on these aspects of local cortical circuitry. However, even apart from polysynaptic connections, the conduction delays involved in direct pathways from the hippocampal formation to the prefrontal cortex may be sufficient to match the theta period.

The effect of this resonance would be that the collection of scattered cells activated by the particular environment would come to have some of the properties of a cell assembly, although its members would not have become interlinked in the manner envisaged for conventional lo- cal cell assemblies. One thus would have a global cell assembly, with the ability to recognize the environment categorically. The ambiguity inherent in the representation of a single image or object that obtains in the absence of a coordinating representation of the environment could thus be resolved. These arguments need not apply to an environment's spatial aspects only, but to background contextual information in general. In effect, by providing the appropriate neural context for resolving ambiguity in the cortical representation of information, specific classes of information stored in memory could be retrieved.

There is an additional possibility for the role of the hippocampal theta rhythm in the scheme presented here: As a result of the entrainment of phase-locked loops, a spatiotemporal structure of strengthened connections is likely to come into being throughout the cortex. This structure may endure long after the bilateral removal of the hippocampus. This possibility may explain the fact that remote memories can be retrieved in human beings after bilateral hippocampal destruction (Scoville \& Milner, 1957).

Experimental studies of hippocampal neurons in freemoving animals show that they may respond specifically when the animal is in a particular place (O'Keefe, 1979). As is to be expected on the basis of the present hypothesis, these neuronal place fields are more distinct when the hippocampus is generating theta activity than when it is not (Muller, Kubie, \& Ranck, 1987). This is a clear indication of one type of environment that may be represented by the cortico-hippocampal interplay.

In effect, this hypothesis may also form a biological basis for the psychological construct of selective attention. Although selective attention is well-founded on the basis of behavioral experiments (Sutherland \& MacKintosh, 1971), it is unclear what (in biological terms) is selected or how. It is suggested here that selective attention involves the selection of just one of a number of different global cell assemblies.

\section{Phase-Locked Loops and Economy of Information Storage}

In this scheme, a neocortical projection neuron involved in a resonant loop might use just one of its connections, specified by its conduction delay, to link it to the hippocampus. However, at the hippocampal end of the loop, the situation would be different: A projection neuron there would have a variety of axon collaterals, each with a different conduction delay (see Figure 2). Each one could take part in specifying different environments, according to its temporal relations with different cortical neurons activated in each environment. One therefore has a potentially more economical way of using connections to represent information than one does if only spatial aspects of connectivity are used. Thus, the insufficiency of connections in a typical cortical neuron to allow global cell assemblies to form by conventional methods (pointed out previously) is overcome. This idea has mathematical implications, which will not be pursued here. 
Some of the empirical evidence about hippocampal place fields strongly suggests a very economical style of representation. A single neuron may have several quite different place fields for use when the animal is in different environments, or it may change its place field in a single environment dramatically when an object in the original place field is shifted (Muller \& Kubie, 1987; O'Keefe \& Conway, 1978). Neighboring hippocampal neurons usually have place fields that bear little relation to one another (O'Keefe, 1976; O'Keefe \& Speakman, 1987). The redundancy evident in the neocortex (e.g., in the columnar representation of visual space) seems to be quite foreign to the hippocampal representation of information.

\section{The Hippocampal Theta Rhythm}

The theta rhythm itself (rhythmic slow activity: RSA) was first described by Jung and Kornmuller (1938). It is a large-scale electrographic pattern, generated in the hippocampus and adjacent structures. The pacemaker for the rhythm is a group of neurons in and near the medial septal nucleus, which emit rhythmic signals along a pathway to the hippocampus (Apostol \& Creutzfeldt, 1974; Bragin \& Vinogradova, 1983; Green \& Arduini, 1954; Petsche, Stumpf, \& Gogolak, 1962; Vinogradova, Braznik, Karanov, \& Zhadina, 1980). (However, note than in vitro, the hippocampus can generate theta-like rhythms on its own in response to cholinergic agonists; see Konopacki, B. H. Bland, \& Roth, 1987.) The septal cells in their turn are thought to be controlled by signals ascending from the brainstem, which are themselves nonrhythmic but are translated into rhythmic activity by neurons in the septal region (Petsche, Gogolak, \& Van Zweiten, 1965; Vertes, 1981). Details of various aspects of the theta rhythm are compatible with the above hypothesis, and in some cases, they seem to point specifically to this hypothesis, rather than others. In the sections below, aspects of the theta rhythm are discussed under the headings of Behavioral Correlates, Effects of Lesions on Theta Activity, and Laminar Profiles of Theta Activity.

\section{Behavioral Correlates of Theta Activity}

These have been investigated in several species, in many studies over the last 30 years. In the early literature, the emphasis was on correlations between theta activity and learning, or correlations with other aspects of information processing. It was observed in a variety of learning situations that theta activity is weak at the start of learning, but that it becomes stronger, or higher in frequency, at the time when performance is improving most rapidly. Such a correlation has been seen in classical conditioning as the signal value of a CS becomes established (Buzsaki, Grastyan, Tveritskaya, \& Czopf, 1979; Buzsaki, Haubenrauser, Grastyan, Czopf, \& Kellenyi, 1981), in appetitive conditioning (Adey, Dunlop, \& Hendrix, 1960; Bennett, 1970; Coleman \& Lindsley, 1977; Grastyan, Karmos, Vereckei, \& Kellenyi, 1966; Grastyan, Lissak,
Madarasz, \& Donhoffer, 1959; Pickenhain \& Klingberg, 1967) and active avoidance learning (Graliewicz, 1981; Grastyan et al., 1966; Grastyan et al., 1959; Lissak \& Grastyan, 1960; Pickenhain \& Klingberg, 1967), and in discrimination tasks (Grastyan et al., 1966; Grastyan et al., 1959; Lissak \& Grastyan, 1966; Pickenhain \& Klingberg, 1967). As the response becomes automatic, theta activity often declines (Adey \& Walter, 1963; Bennett, 1970; Elazar \& Adey, 1967; Grastyan et al., 1966; Grastyan et al., 1959; Grastyan \& Vereckei, 1974; Lissak \& Grastyan, 1960; Pickenhain \& Klingberg, 1967; Porter, Adey, \& Brown, 1964). Although this evidence is extensive, no consensus has been reached concerning its significance or exactly what aspect of information processing was correlated with theta activity.

More recently, the emphasis has shifted to correlations with aspects of behavior other than those found in learning tasks. It appears that there are important species differences in the correlates of theta activity within this broad class of behaviors. In rats and other small-brained animals, theta activity is particularly associated with certain types of body movements (Kramis, Vanderwolf, \& B. H. Bland, 1975; Vanderwolf, 1969; Whishaw \& Vanderwolf, 1973). The frequency of the theta rhythm is lower for small movements from a fixed base than for whole-body movements such as locomotion. Immobile rats do not show theta activity except under rather special circumstances, such as under curare (Macadar, Roig, Monti, \& Budelli, 1970), during the deep relaxation of REM sleep (Vanderwolf, Kramis, \& Robinson, 1978), or in the brief immobile period before a jump (Vanderwolf, 1975). Rabbits are in many respects like rats, but there is an additional tendency for theta activity to occur in the immobile animal in response to sudden stimuli (Kramis et al., 1975). In cats, theta activity can occur during locomotion, but it is also very prominent in the immobile animal, in association with orienting responses (Brown, 1968; Coleman \& Lindsley, 1975; Whishaw \& Vanderwolf, 1973). With respect to primates, there have been few studies, and theta activity has been difficult to recognize unless spectral analysis is performed (Crowne \& Radcliffe, 1975; Pribram, 1986).

However, although nowadays these evident correlations between theta activity and overt behavior are receiving the greatest attention in the literature, there are plenty of exceptions in which the dominant correlations do not apply so well. Many of these exceptions have been obtained in the course of learning experiments. In some experiments, locomotor activity can occur in the absence of theta rhythms. In the experiments of Routtenberg (1968), in which several days of habituation to an initially novel enclosure occurred, there was very little theta activity on the later days, although the animal still walked about. Pickenhain and Klingberg (1967) presented repeated shocks to rats, either unsignaled or signaled, along with the opportunity for them to learn avoidance responses. In the unsignaled situation, it was observed that the animals ini- 
tially made chaotic attempts to escape, which were not accompanied by hippocampal RSA, but that when the first successful avoidance responses occurred, so did RSA.

Some data also show that theta activity can occur during learning in the absence of locomotor or other wholebody movements. For instance, Pickenhain and Klingberg (1967) used rats in the situation of signaled avoidance learning (with repeated flash as a warning signal). When the avoidance response was well learned, the signal presented on each trial evoked hippocampal RSA well before any avoidance response occurred, and in the absence of other motor behavior. Similar exceptions in the detailed correlation between locomotion and theta activity have been seen by Bennett (1975) in DRL experiments, by Schwartzbaum (1975) during training of a conditioned emotional response, and by Buzsaki, Grastyan, Kellenyi, and Czopf (1979), in a classical conditioning task in which responding to the UCS was differentiated from that to the CS. In the latter study, it was found that hippocampal RSA was concentrated in the 1st second of the 2-sec CS-UCS interval, in relation to CS-directed behavior (i.e., orienting). As training proceeded, UCS-directed behavior (in the 2nd second) gradually increased, but without any association with hippocampal RSA in this period.

In summary, the correlations emphasized by Vanderwolf and colleagues with respect to theta activity and various types of behavior unrelated to learning are clearly established. However, they are only correlations, not explanations of theta activity. They can therefore coexist, without logical contradiction, with the other correlations (for instance those emphasized by the early literature, and supported by evidence such as the above exceptions to Vanderwolf's conclusions). There would seem to be a need for reconciliation between the older literature emphasizing correlations with learning, and the newer literature, which is more behavioristic.

It may be suggested that the following principles might bring some order to this complex body of literature:

1. Theta activity can be generated without entraining resonant loops with the cortex. This is the baseline theta activity, akin to an automobile's idling without engaging the gears. In this case, the behavioral correlates of theta activity are a number of species-specific innate forms of behavior. These correlates are probably coordinated by hardwired brainstem mechanisms, whose ascending influence controls the septal pacemaker. Much of the literature on this can be summed up by the suggestion that in each species, theta activity occurs during the behavior which that species, in its natural habitat, uses for gathering information from the environment. This generalization includes exploration in rats, alertness to warning signals in rabbits, and preparations for stalking prey in cats. In primates, it may be that the adequate situations for theta-activity production in these highly social species are those involving social triggers. The investigations conducted so far have not addressed this possibility. Although there seems to be some validity in this ecological generalization (i.e., the circumstances tending to be associated with information gathering), the occurrence of theta activity in these species-specific correlations does not necessarily mean that information gathering must be taking place. For this to occur, other conditions must be fulfilled.

2. It is known that an increase in neural activity in the pathways ascending from the brainstem to the septal region can increase the frequency of theta activity. Some of the species-specific correlates of theta activity may therefore also be associated with specific frequencies of theta activity. This may underlie the fact that low-frequency theta activity in rats is associated with small movements from a fixed base, while more vigorous whole-body movement is associated with an increase in theta frequency.

3. Only under certain circumstances may theta activity entrain the cortex into resonant activity. In this case, the innate species-specific forms of behavior may not be the only important correlate of theta activity. There may, in addition, be aspects of information processing, generalizable across species, that correlate with theta activity. Both types of correlation may sometimes be observable at the same time in such circumstances.

4. In small-brained mammals, the theta rhythm is more likely to entrain the cortex into resonant activity if the baseline theta is in the upper end of the frequency range. This is because it is only at this higher frequency that the theta period is small enough to match the repertoire of delay times in the axonal loops between the hippocampus and the isocortex.

5. The information processing accomplished when the hippocampus and cortex are entrained into resonant activity allows context-dependent learning to occur that otherwise would not occur. In overtrained tasks, however, the memory trace may be so strongly stamped into the cortical network that it no longer needs a context representation. For instance, consider a stimulus that has occurred very often, and almost always in one context, the requirement being to elicit only one variety of response. Such a stimulus can be treated as it would be in stimulusresponse theory, rather than as a key to activate a cell assembly. It would then not require the context representation, because there would be little ambiguity to resolve. This theoretical derivation is supported by the concept put forward by Mishkin and Petri (1984) - that acquired representations of information may be divided into two classes, habits and memories, with only the latter requiring the information-processing advantages of an intact hippocampus.

6. It is known that the septal mechanisms controlling the baseline theta activity can be operantly conditioned by the effect of the behavioral response, just as can the overt behavioral response (Black, 1975; Black, Young, \& Batenchuk, 1970; Dalton, 1969). It is suggested here that this is not just a peculiarity of certain experiments; it plays an important role in some instances of instrumental conditioning. In particular, at the time when a new response is only partially learned, the response may be especially dependent on the setting up of the matching context of neural activity to resolve ambiguity. When this neu- 
ral context exists, so that the response occurs correctly, both the behavioral response and the electrographic conditions that bring about the obtaining of reward will be reinforced. The electrographic condition that brings about reward is the production of theta activity that allows resonance to develop between the hippocampus and cortex, thus defining the neural context for the correct performance of the task. When, at a later stage of training, the response occurs automatically, reward is guaranteed regardless of the concomitant neural context. Therefore, at this stage of learning, there will be no differential reinforcement of theta activity associated with a correct behavioral response, and theta activity will decline. This is precisely the observation made in many of the early studies of learning correlates of theta activity (see above).

In the sections below, further evidence is presented for the concept that resonant loops between the hippocampus and cortex, phase-locked to the theta rhythm, play an important part in information processing. The evidence concerns particularly the difference between the anesthetized preparation (which, according to the above postulates, should be merely "idling," without entraining the cortex in theta activity), and preparation from the free-moving rat or rabbit (when entrainment might take place).

\section{Effects of Lesions on Theta Activity}

In the most thoroughly investigated species, the rat (with some confirmation in other species), there appear to be two types of theta activity, distinguishable by frequency range as well as vulnerability to drugs and lesions (Table 1). Type 1 theta activity, which has a higher frequency range, correlates with locomotor activity, and it is blocked by anesthetics such as urethane. Type 2 theta activity, which has a lower frequency range, survives anesthetics, but it is blocked by muscarinic blockers. From the present point of view, the most interesting fact is that the highfrequency (Type 1) theta activity related to locomotor activity becomes abolished when lesions disconnect the hippocampus from the neocortex, leaving only the lowfrequency, atropine-sensitive component. On the other hand, lesions that spare the cingulate cortex and cingulum bundle have relatively little effect. One explanation of these findings is that atropine-resistant pacemaker signals are transmitted from the septum to the hippocampus not over the traditional septo-hippocampal pathway in the fornix, but over a route in front of and above the corpus callosum by way of the cingulum bundle (Vanderwolf,
Leung, \& Cooley, 1985). The evidence is equally compatible, however, with the idea that axonal loops between the hippocampus and the cortex can establish resonances, preferring the higher frequencies of theta, such as those produced in the free-moving rat unaffected by urethane. It is worth pointing out here that the cingulate cortex is one of the regions most strongly connected to the hippocampus, and that the cingulum bundle may well be the major trajectory of the axons linking the hippocampus with the prefrontal cortex. The relatively small effect of lesions that spare these sites is also thus explained. Indeed this explanation seems preferable to that offered by Vanderwolf et al. (1985), because lesions of the fornix that leave the septum and the hypothetical supracallosal pathway intact abolish completely all types of theta activity in vivo (Vinogradova \& Braznik, 1978; Vinogradova et al., 1980). Therefore, Type 1 theta activity appears to depend on the integrity both of pathways passing from the septum to the hippocampus by way of the fornix and of pathways passing between the hippocampus and the neocortex behind the corpus callosum. There is little evidence of a pathway for theta activity independent of the fornix.

\section{Laminar Profiles of Theta Activity}

Some of the most detailed evidence for the proposed interaction between the hippocampus and the cortex comes from consideration of the profile of theta activity in different laminae of the hippocampus. Again there exist some very interesting data on the differences between theta rhythms in preparations from anesthetized and freemoving animals.

Not only are there two types of theta activity, but for each type there are at least two sites of generation within the hippocampus. The precise situation is different for Type 2 theta activity (e.g., the urethanized rat) as compared with Type 1 theta activity (e.g., the free-moving rat; see the schematic illustration in Figure 3). In the urethanized rat in field CA1, there is an abrupt phase reversal in theta activity in the proximal stratum radiatum, with a definite point of almost zero amplitude, and a maximum amplitude (of the reversed potentials) below this at the level of the hippocampal fissure (Buzsaki, Czopf, Konakor, \& Kellenyi, 1986; Feenstra \& Holsheimer, 1979; Leung, 1984b). Phase reversal might arise from the dipole generated by a single source of synaptic current located in a circumscribed part of the dendritic trees (Rall, 1962). However, computer models of potentials in this region

Table 1

Types of Theta Activity in the Rat

\begin{tabular}{|c|c|c|}
\hline & Type 1 & Type 2 \\
\hline $\begin{array}{l}\text { Behavioral correlate } \\
\text { Frequency range } \\
\text { Blocking drugs } \\
\text { Blocking lesions }\end{array}$ & $\begin{array}{l}\text { Vigorous whole body movements } \\
6-12 \mathrm{~Hz}^{2} \\
\text { Anesthesia (especially urethane) } \\
\text { Septum } \\
\text { Disconnection of cortex from hippocampus } \\
\text { Di,6.7 }\end{array}$ & $\begin{array}{l}\text { Movements of small segments of body }{ }^{1,2} \\
4-7 \mathrm{~Hz}^{2} \\
\text { Muscarinic blockers }^{1} \\
\text { Septum }^{3,4} \text {; fornix }\end{array}$ \\
\hline
\end{tabular}

${ }^{1}$ Kramis et al. (1975); ${ }^{2}$ Vanderwolf (1969); ${ }^{3}$ S. K. Bland and B. H. Bland (1986), Green and Arduini (1954), Winson (1978);

${ }^{4}$ Vinogradova and Braznik (1978); ${ }^{5}$ Vanderwolf et al. (1985); ${ }^{6}$ Vanderwolf and Leung (1983); ${ }^{7}$ Montoya and Sainsbury (1985). 

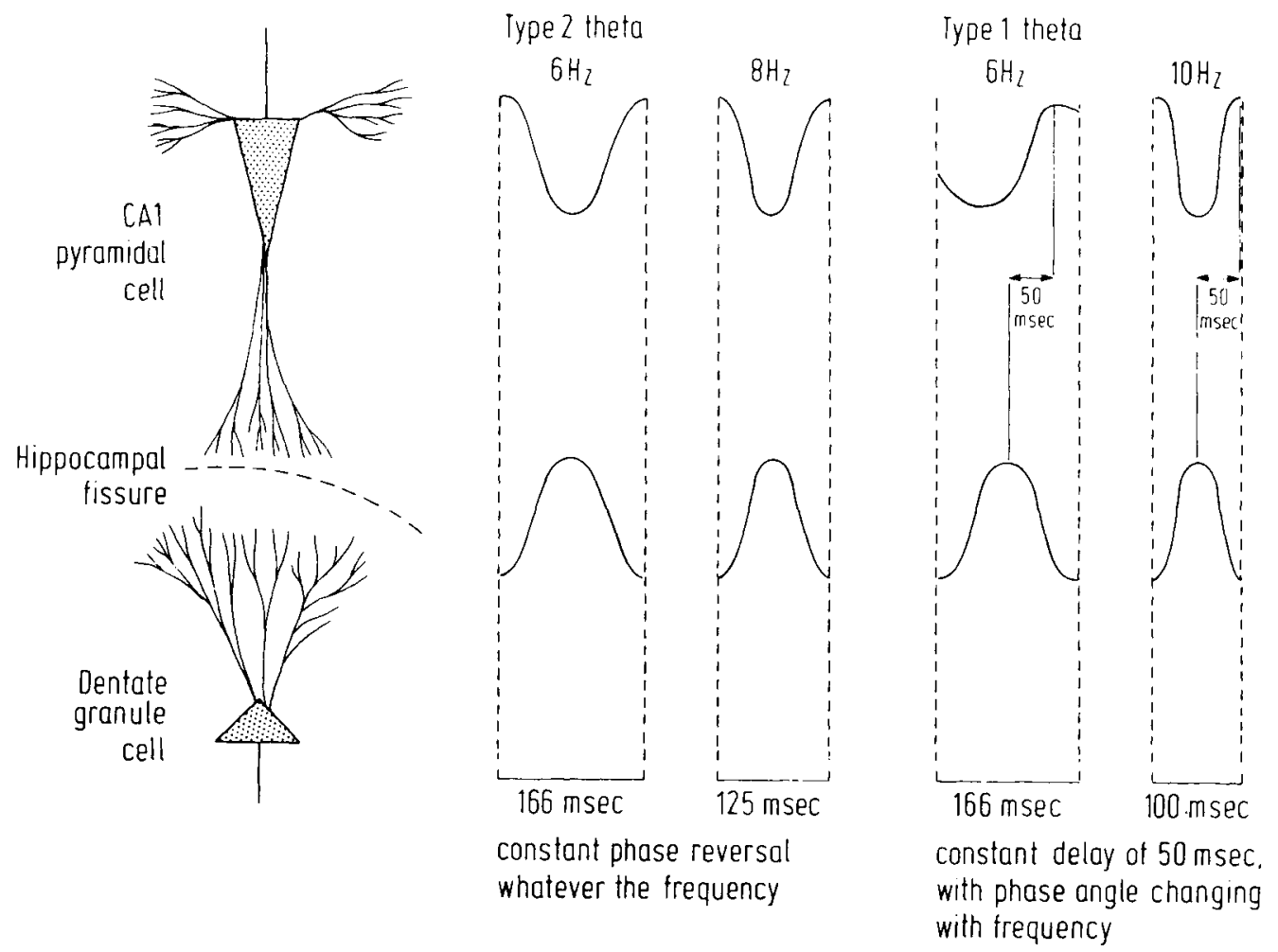

Figure 3. Schematic illustration of phase relations between superficial (pyramidal cell layer of CAI) and deep (stratum radiatum of CA1, and, putatively, the dentate gyrus) theta generators. In Type II theta, there is a phase reversal that stays constant, despite variations in frequency. In Type I theta, the superficial generator lags behind the deep one by an interval of about $50 \mathrm{msec}$, which remains constant with varying theta frequency, while phase difference varies. Thus, at $6 \mathrm{~Hz}$ the superficial theta generator lags the deep one by $108^{\circ}$; at $10 \mathrm{~Hz}$, it lags by $180^{\circ}$.

indicate that there must be at least two dipoles (Holsheimer, Boer, Lopes da Silva, \& Van Rotterdam, 1982). There are other empirical data that oppose the idea of a single dipole: In the dentate gyrus, unit firing near the granule cell layer tends to be $180^{\circ}$ out of phase with that recorded in the CAl pyramidal cell layer (B. H. Bland, Andersen, Ganes, \& Sveen, 1980; Buzsaki \& Eidelberg, 1983; Fox, Wolfson, \& Ranck, 1983).

Such phase reversal between different parts of the hippocampus has been seen in many circumstances, and it appears to hold regardless of variation in theta frequency (see Leung, 1984b, Table 2). If different parts of the proposed connectional loops display neural activity resonating at the theta frequency, with phase determined by conduction delays, one would not expect this pattern; one would rather expect a pattern of constant delay, with phase angle changing with frequency. However, there are indications that in the free-moving rat, the latter relation does in fact hold.

In the free-moving rat, the phase shift that occurs in stratum radiatum of CA1 is not abrupt, as in the urethanized rat, but rather gradual, taking place over about $400 \mu \mathrm{m}$ of dendritic length, there being a point of minimum amplitude in this region, but no null point (Buzsaki et al., 1986; Winson, 1974). In addition, the total phase shift along an electrode track passing from CA1 into the dentate gyrus is often significantly less than $180^{\circ}$, ranging from about $100^{\circ}$ to $180^{\circ}$ (dentate gyrus leading; see Leung, 1984c; Leung, Lopes da Silva, \& Wadman, 1982).

There have been a number of suggestions that the size of this phase shift may have some meaning in relation to behavior (Brown, 1968; Buzsaki et al., 1979). The most precise analysis is that of Leung (1984c; see also Leung, 1984a), who found, both for free-moving rats and for rats during REM sleep, that there is an orderly quasilinear relation between theta frequency and the phase shift observed between superficial and deep laminae of CA1. In other words, at the higher theta frequency, the phase shift is as much as $180^{\circ}$, whereas at lower frequencies, it amounts to only about $120^{\circ}$ phase lead by the deep source. Leung calculates that this represents a constant delay of about 30-50 msec (rather than a constant phase difference) of the superficial with respect to the deep synaptic inputs (see Figure 3). Note that a theoretical paper by Leung (1984a) adds to this interpretation, but it appears to contain a source of confusion as well, which is discussed in the present Appendix.

We already have reason to believe (Table 1) that in the free-moving rat, theta activity depends in part on an input from the neocortex (Montoya \& Sainsbury, 1985; Vanderwolf \& Leung, 1983; Vanderwolf et al., 1985). It is therefore likely that this involves theta-modulated sig- 
nals arriving from the entorhinal cortex along the perforant path. This is the synaptic input considered by Leung (1984a) to be the distal dendritic source of theta potentials in CA1. However, this path is afferent not only to the apical dendrites of the CA fields (as considered by Leung), but also to the dendrites of the dentate granule cells. Consequently, it would be expected that the theta activity generated in the dentate gyrus likewise leads that in the CAl pyramidal cell layer by a similar constant delay in the free-moving rat. This issue has not been adequately addressed experimentally. Leung (1984c) mentions some experiments in which phase/frequency relations have been studied for comparisons between the superficial theta sources and the dentate gyrus. These experiments did not show the systematic relation postulated above for comparisons with stratum radiatum. However, this negative result appears to be based on only a few tracks, and the detailed data is not presented. The topic deserves further investigation.

It is suggested that this constant delay of $30-50 \mathrm{msec}$ (derived by Leung), of superficial CA1 theta with respect to theta in deep CAl and (by implication) in the dentate gyrus, is mainly an axonal conduction delay of theta activity relayed from the dentate gyrus to CA1. This figure is therefore used to derive the conduction delay through the hippocampal part of the resonant loops (depicted in Figure 1 as " 40 msec").

In the unanesthetized rabbit, it has been said that theta profiles are more like those of the urethanized than the free-moving rat (Winson, 1976). However, Winson's paper does not give detailed data on phase relations at different depths, merely a general statement that phase reversal was sharp. It is therefore important that analyses be performed for the free-moving rabbit, similar to those carried out by Leung, and by Buzsaki's group, in freemoving rats.

If, in free-moving preparations, there is a constant delay of theta activity in CA1 with respect to that in the dentate gyrus, the inference is that the dentate gyrus must be controlling theta activity in CA1. If this is so, one would expect that the pathway from dentate to $\mathrm{CA} 1$, through field CA3, should also carry theta-modulated signals. Although this appears not to be so in the urethanized rat (B. H. Bland, Andersen, \& Ganes, 1975; B. H. Bland \& Whishaw, 1976; Green \& Rawlins, 1979), data from Buzsaki et al. (1986) show that, as expected, field CA3 does generate theta potentials in the free-moving rat.

In summary, the evidence gives some support for the general scheme of self-organizing phase-locked loops: It demonstrates that in the information gathering mode of an animal's behavior, when, according to lesion evidence, entrainment between the hippocampus and the cortex may occur, the conditions are actually established for completion of these loops, at least within the hippocampus itself. When these resonant loops are completed, the Hebbian mechanism can then be recruited at various parts of the loop, thus strengthening further the tendency for neural activity to resonate at the theta frequency.

\section{Spatio-Temporal Aspects of Theta Activity During Learning}

The view of hippocampo-cortical relations advanced above is essentially dynamic. The neocortex, by virtue of its direct relations with the environment, is continually remodeling its representation of items in the environment. At the same time, the hippocampo-cortical connections are correspondingly readjusting their representation of the environment as a whole, as a result of less direct influences from the environment. As expected, during learning processes, there are systematic changes in the occurrence of theta activity (see above). In addition, during learning, there should be systematic changes in this activity's spatial distribution in the brain, in its frequency, and in its mutual phase relations in different structures. In the early literature, there are examples of all these predictions.

Results obtained by Adey and coworkers in the 1960s provide some of the most substantial evidence compatible with the present hypothesis. For instance, cats acquiring a visual T-maze discrimination showed theta activity initially confined to the CA fields, but as acquisition proceeded, it came to be recordable elsewhere (dentate gyrus and subiculum; see Radulovacki \& Adey, 1965). Frequency shifts in theta activity during the course of learning have been described. For instance, an irregular 4-7 $\mathrm{Hz}$ activity at the start of conditioning on an appetitive task evolved to a much more regular $5-\mathrm{Hz}$ rhythm as the task was acquired (Adey et al., 1960). Most striking are the data of systematic shifts in phase relations between different structures as conditioning proceeds. In an approach-learning task, cats initially generated in CA fields a theta activity that had a phase lead over that in the entorhinal cortex. As conditioning proceeded, the entorhinal theta activity came to have a phase lead over that in CA fields (Adey et al., 1960). This result seems to imply that during learning there is a development of control of theta in the hippocampus by theta-modulated inputs from the entorhinal cortex. As a whole, the above results seem to be examples of the spatial spread of theta activity and its stabilization with regard to frequency and phase as resonant loops between the hippocampus and the cortex become established. A later experiment from Adey's laboratory involved visual discrimination in a Tmaze. On correct trials, theta activity in the entorhinal cortex had a consistent phase lead over that in the CA fields, while on incorrect trials, the reverse phase relation was seen (Adey, Walter, \& Hendrix, 1961; see also the corrigendum in Walter \& Adey, 1963, p. 488, n.). This suggests that when activity in resonant loops is overridden by other activity, performance of a recently learned task may fail for that reason.

\section{Some Predictions}

The most definite evidence for this hypothesis comes from the study of phase relations of theta activity in different parts of the hippocampal formation. Given the present hypothesis, much further work of the same sort remains 
to be done. For instance, regions such as the entorhinal cortex (Adey et al., 1960; Alonso \& Garcia-Austt, 1987a, 1987b; Mitchell \& Ranck, 1980) and the cingulate cortex (Borst, Leung, \& McFabe, 1987; Feenstra \& Holsheimer, 1979; Holsheimer, 1982; Leung \& Borst, 1987) are known to be capable of generating theta activity, but there is no data on the phase relations between it and simultaneous theta activity in the hippocampus. The most definite prediction made here is that there should be rhythmic neural activity, phase-locked to the hippocampal theta rhythm, in areas of the cortex other than those directly linked to the hippocampus. This has so far not been seen, but I believe that this is because relatively large electrodes are generally used to record cortical EEGs. These would record signals from the cortical end of many different loops at once, all with the same frequency but each with different phase relations (see Figure 2). The phase-locking of any one cortical node would thus be obscured by spatial averaging. With finer electrodes, and improved statistical techniques, these technical difficulties can be overcome (see Thatcher, Krause, \& Hrybyk, 1986), and the prediction tested.

One further point requires clarification and leads to further predictions. There is no suggestion here that different environments can be encoded by different frequencies of theta. A single dominant frequency can entrain a variety of different sets of resonant loops in different environments. However, it can be predicted that if the theta frequency during retrieval of memory departs sufficiently from the theta frequency during that memory's acquisition, then retrieval may fail. In the older psychological literature, there are suggestions of such an effect: the socalled Yerkes-Dodson principle (Yerkes \& Dodson, 1908) claims that the relation between level of arousal and performance level is that of an inverted U. Assuming that progressive increase in the level of arousal is accompanied by progressive increase in the frequency of theta pacing in the septal region, one would predict that there would be an optimum frequency of theta activity (and arousal level) at which memory retrieval could occur most readily. The maximum point on this curve might correspond to the theta frequency present during initial learning of the task.

A related prediction can be made for experiments on learning in rats. It was argued above that in rats and similar small-brained animals, rhythmic entrainment of the cortex occurred more easily during the higher frequency theta rhythm associated with locomotion than during lowfrequency theta activity. Therefore, context-dependent memory retrieval should be accomplished more effectively in a rat that is moving around than in one that is immobile or moving from a fixed base. However, the design of an experiment to test this prediction would be somewhat problematic. It is also likely that there will not be an absolute impairment of context-dependent memory retrieval in the stationary rat, because hippocampal neurons in rats do show definite place fields when no theta activity is discernible, albeit weaker ones than during theta activity.

\section{Summary and Comment}

In small neural networks, cell assemblies can form using plausible connectivity ratios and Hebbian processes of synaptic modification. These can represent small-scale patterns, such as those defined in terms of stimuli and responses. However, these anatomical and physiological features are insufficient to form cell assemblies that represent the environment as a whole, because individual neurons cannot make sufficient connections. Small-scale patterns (representations of objects and response intentions) that are ambiguous unless the environment is specified cannot be represented in a manner that allows unambiguous retrieval.

The hypothesis presented in this paper provides a means of overcoming these limitations. Patterns of resonant loops between the hippocampus and the rest of the cortex are envisaged to define the global cell assemblies that can represent different environments as wholes. These patterns of resonant loops are envisaged as organizing themselves through selection from the existing repertoire of reciprocal pathways. The selection depends on the Hebbian paradigm for synaptic modification, together with the theta rhythm generated by the hippocampus as a neural oscillator. These two features determine the choice of just those sets of axons whose total loop time corresponds to the period of the theta rhythm. Thus, the patterns of strengthened connections that are selected utilize the temporal as well as the spatial aspects of axonal connectivity, and the available connections are used more economically than in a conventional cell assembly.

This hypothesis forms a foundation on which the psychological ideas of selective attention, context-dependent manipulation of information, and their relation to learning processes can be biologically based.

\section{REFERENCES}

Adey, W. R., Dunlop, C. W., Hendrix, C. E. (1960). Hippocampal slow waves: Distribution and phase relationships in the course of approach learning. Archives of Neurology, 3, 74-90.

ADEY, W. R., \& WALTER, D. O. (1963). Application of phase detection and averaging techniques in computer analysis of EEG records in the cat. Experimental Neurology, 7, 186-209.

Adey, W. R., Walter, D. O., Hendrix, C. E. (1961). Computer techniques in correlation and spectral analyses of cerebral slow waves during discriminative behavior. Experimental Neurology, 3, 501-524.

Alonso, A., Garcin-Austr, E. (1987a). Neuronal sources of theta rhy thm in the entorhinal cortex of the rat: I. Laminar distribution of theta field potentials. Experimental Brain Research, 67, 493-501.

Alonso, A., GARCIA-AUSTT, E. (1987b). Neuronal sources of theta rhythm in the entorhinal cortex of the rat: II. Phase relationships between unit discharges and theta field potentials. Experimental Brain Research, 67, 502-509.

Apostol, G., \& Creutzfeldt, O. D. (1974). Cross correlation between the activity of septal units and hippocampal EEG activity during arousal. Brain Research, 67, 65-75. 
BENNETT, T. L. (1970). Hippocampal EEG correlates of behaviour. Electroencephalography \& Clinical Neurophysiology, 28, 17-23.

BENNETT, T. L. (1975). The electrical activity of the hippocampus and processes of attention. In R. I. Isaacson \& K. H. Pribram (Eds.), The hippocampus (Vol. 2, pp. 71-99). New York: Plenum.

BLACK, A. H. (1975). Hippocampal electrical activity and behavior. In R. I. Isaacson and K. H. Pribram (Eds.), The hippocampus (Vol. 2, pp. 129-168). New York: Plenum.

Black, A. H., Young, G. A., \& Batenchuk, C. (1970). Avoidance training of the hippocampal theta waves in flexedilised dogs and its relation to skeletal movement. Joumal of Comparative \& Physiological Psychology, 70, 15-24.

Bland, B. H., Andersen, P., \& Ganes, T. (1975). Two generators of hippocampal theta activity in rabbits. Brain Research, 94, 199-218.

Bland, B. H., Andersen, P., Ganes, T., \& Sveen, O. (1980). Automated analysis of thythmicity of physiologically identified hippocampal formation neurons. Experimental Brain Research, 38, 205-219.

BLAND, B. H., \& WHISHAW, I. Q. (1976). Generators and topography of hippocampal theta (RSA) in the anaesthetized and freely moving rat. Brain Research, 118, 259-280.

BLAND, S. K., \& BLAND, B. H. (1986). Medial septal modulation of hippocampal theta cell discharges. Brain Research, 375, 102-116.

Borst, J. G. G., Leung, L. W.-S., \& McFabe, D. F. (1987). Electrical activity of the cingulate cortex: II. Cholinergic modulation. Brain Research, 407, 81-93.

Bragin, A. G., Vinogradova, O. S. (1983). Comparison of neuronal activity in septal and hippocampal grafts developing in the anterior eye chamber of the rat. Developmental Brain Research, 10, 279-286.

Brattenberg, V. (1977). On the texture of brains. Heidelberg: Springer. BRINDLEY, G. S. (1967). The classification of modifiable synapses and their use in models for conditioning. Proceedings of the Royal Society of London, Series $B, 168,361-376$.

Brodal, A. (1969). Neurological anatomy. Oxford, England: Oxford University Press.

BrowN, B. B. (1968). Frequency and phase of hippocampal theta activity in the spontaneous behaving cat. Electroencephalography \& Clinical Neurophysiology, 24, 53-62.

Buzsaki, G., Czopf, J., Konakor, I., \& Kellenny, L. (1986). Laminar distribution of hippocampal rhythmic slow activity (RSA) in the behaving rat: Current source density analysis, effects of urethane and atropine. Brain Research, 365, 125-137.

BUzsaKI, G., \& EIDElBERG, E. (1983). Phase relations of hippocampal projection cells and interneurons to theta activity in anaesthetized rat. Brain Research, 266, 334-339.

Buzsaki, G., Grastyan, E., Kellenyi, L., \& Czopf, J. (1979). Dynamic phase-shifts between theta generators in the rat hippocampus. Acta Physiologica Academiae Scientiarum Hungaricae, 53, 41-45.

Buzsaki, G., Grastyan, E., Tvertsskaya, I. N., \& Czopf, J. (1979). Hippocampal evoked potentials and EEG changes during classical conditioning in the rat. Electroencephalography \& Clinical Neurophysiology, 47, 64-74.

Buzsaki, G., Haubenrauser, J., Grastyan, E., Czopf, J., \& KellenYI, L. (1981). Hippocampal slow wave activity during appetitive and aversive conditioning in the cat. Electroencephalogra phy \& Clinical Neurophysiology, 51, 276-290.

Cavada, C., Llamas, A., \& Reinoso-Suarez, F. (1983). Allocortical afferent connections of the prefrontal cortex in the cat. Brain Research, 260, 117-120.

Coleman, J. R., \& Lindsley, D. B. (1975). Hippocampal electrical correlates of free behavior and behavior induced by stimulating two hypothalamo-hippocampal systems in the cat. Experimental Neurology, 49, 506-528.

COLEMAN, J. R., \& LINDSLEY, D. B. (1977). Behaviour and hippocampal electrical changes during operant learning in cats and effects of stimulating two hypothalamo-hippocampal systems. Electroencephalography \& Clinical Neurophysiology, 42, 309-331.

Creutzfeldt, O., \& Ito, M. (1968). Functional synaptic organization of primary visual cortex neurons in the cat. Experimental Brain Research, 6, 324-352.

Creutzfeldt, O., Maekawa, K., \& Hosu, L. (1969). Forms of evoked and spontaneous postsynaptic potentials of cortical nerve cells. Progress in Brain Research, 31, 265-273.

Crowne, D. P., RADClifFE, D. D. (1975). Some characteristics and functional relations of the electrical activity of the primate hippocampus and hypotheses of hippocampal function. In R. I. Isaacson \& $\mathbf{K}$. H. Pribram (Eds.), The hippocampus (Vol. 2, pp. 185-206). New York: Plenum.

Dalton, A. J. (1969). Discriminative conditioning of hippocampal electrical activity in curarised dogs. Communications in Behavioral Biology, 3, 283-287.

ElAZAR, Z., \& ADEY, W. R. (1967). Spectral analysis of low frequency components in the electrical activity of the hippocampus during learning. Electroencephalography \& Clinical Neurophysiology, 23, 225-240.

FeEnstra, B. W. A., \& Holsheimer, J. (1979). Dipole-like neuronal sources of theta rhythm in dorsal hippocampus, dentate gyrus and cingulate cortex of urethane-anaesthetised rats. Electroencephalography \& Clinical Neurophysiology, 47, 532-538.

Ferino, F., THIERRY, A. M., GlowinSKI, J. (1987). Anatomical and electrophysiological evidence for a direct projection from Ammon's horn to the medial prefrontal cortex in the rat. Experimental Brain Research, 65, 421-426.

Ferraya Moyano, H., \& Molina, J. C. (1980). Axonal projections and conduction properties of olfactory peduncle neurons in the rat. Experimental Brain Research, 39, 241-248.

Fleischhauer, K., \& Wartenberg, H. (1967). Electronenmikroscopische Untersuchungen über das Wachstum der Nervenfasern und über das Auftreten von Markschneiden im Corpus Callosum der Katze. Zeitschrift für Zellforschung und microscopische Anatomie, 83, 508-518.

Fox, S. E., Wolfson, S., \& RANCK, J. B., JR. (1983). Investigating the mechanisms of hippocampal theta rhythm: Approaches and progress. In W. Seifert (Ed.), Neurobiology of the hippocampus (pp. 303-319). London: Academic Press.

Geschwind, N. (1965a). Disconnexion syndromes in animals and man: Part 1. Brain, 88, 237-294.

Geschwind, N. (1965b). Disconnexion syndromes in animals and man: Part 2. Brain, 88, 585-644.

Gondard, G. V. (1980). Component properties of the memory machine. In P. W. Jusczyk \& R. M. Klein (Eds.), The nature of thought: Essays in honour of D. O. Hebb (pp. 231-247). Hillsdale, NJ: Erlbaum.

Goldman-Rakic, P. S., Selemon, L. D., SChwartz, M. L. (1984). Dual pathways connecting the dorso-lateral prefrontal cortex with the hippocampal formation and parahippocampal cortex in the rhesus monkey. Neuroscience, 12, 719-743.

GraLIEWICZ, C. (1981). Hippocampal electrophysiological correlates of an avoidance behaviour in the cat. Electroencephalography \& Clinical Neurophysiology, 52, 306-315.

Grastyan, E., Karmos, G., Vereckei, L., \& Kellenyi, L. (1966). The hippocampal electrical correlates of homenstatic regulation of motivation. Electroencephalography \& Clinical Neurophysiology, 21, 34-53.

Grastyan, E., Lissak, K., Madarasz, I., \& Donhoffer, H. (1959). Hippocampal electrical activity during the development of conditioned reflexes. Electroencephalography \& Clinical Neurophysiology, 11, 409-430.

Grastyan, E., VereckeI, L. (1974). Effects of spatial separation of the conditioned signal from the reinforcement: $A$ demonstration of the conditioned character of the orienting response or the orientational character of conditioning. Behavioral Biology, 10, 121-146.

Green, J. D., \& ARDUINI, A. A. (1954). Hippocampal electrical activity in arousal. Journal of Neurophysiology, 17, 533-547.

GreEN, K. F., \& RAwLINs, J. N. D. (1979). Hippocampal theta in rats under urethane. Electroencephalography \& Clinical Neurophysiology, 47, $420-429$.

Gustafsson, B., \& Wigström, H. (1986). Hippocampal long-lasting potentiation produced by pairing single volleys and brief conditioning tetani in separate afferents. Journal of Neuroscience, 6, 1575-1582. HeBb, D. O. (1949). Organization of behavior. New York: Wiley. HOLSHEIMER, J. (1982). Generation of theta activity (RSA) in the cingulate cortex of the rat. Experimental Brain Research, 47, 309-312. Holsheimer, J., Boer, J., Lopes da Silva, F. H., \& VAN RotTer- 
DAM, A. (1982). The double dipole model of theta rhythm generation: Simulation of laminae field potential profiles in dorsal hippocampus of the rat. Brain Research, 235, 31-50.

Insausti, R., Amaral, D. G., CoWAN, W. M. (1987). The entorhinal cortex of the monkey: II. Cortical afferents. Journal of Comparative Neurology, 264, 356-395.

IrLE, E., MARKowtrsch, H. J. (1982). Connections of the hippocampal formation, mammilary bodies, anterior thalamus and cingulate cortex. Experimental Brain Research, 47, 79-94.

ITo, M. (1986). Long-term depression as a memory process in the cerebellum. Neuroscience Research, 3, 531-539.

JuNG, R., KoRnMUlLER, A. E. (1938). Eine Methodik der Abkitung lokalisierter Potentialschwangungen aus subcorticalen Hirngebieten. Archiv fur Psychiatrie und Nervenkrankheiten, 109, 1-30.

KoHLER, W. (1938). Physical Gestalten. In W. D. Ellis (Ed.), A source book of Gestalt psychology (pp. 17-54). London: Kegan Paul, Trench, \& Trubner.

KoHONEN, T. (1977). Associative memory. Heidelberg: Springer

Konopackı, J., Bland, B. H., \& Roth, S. H. (1987). Phase shifting of CA1 and dentate EEG rhythms in hippocampal formation slices. Brain Research, 417, 399-402.

Kramis, R. C., Vanderwol.F, C. H., \& Bland, B. H. (1975). Two types of hippocampal slow activity in both the rabbit and the rat: Relations to behavior and effects of atropine, diethyl ether, urethane and pentobarbital. Experimental Neurology, 49, 58-85.

Lee, K. H., Chung, K., Chung, J. M., Coggeshall, R. E. (1986). Correlation of cell body size, axon size and signal conduction velocity for individually labelled dorsal root ganglion cells in the cat. Joumal of Comparative Neurology, 243, 335-346.

LEUNG, L. W.-S. (1984a). Model of gradual phase shift of theta rhythm in the rat. Journal of Neurophysiology, 52, 1051-1065.

LeUNG, L. W.-S. (1984b). Pharmacology of theta phase shift in the hippocampal CA1 region of freely moving rats. Electroencephalography \& Clinical Neurophysiology, 58, 457-466.

LEUNG, L. W.-S. (1984c). Theta rhythms during REM sleep and waking: Correlation between power, phase and frequency. Electroencephalography \& Clinical Neurophysiology, 58, 553-564.

LEUNG, L. W.-S., BorST, J. G. G. (1987). Electrical activity of the cingulate cortex: 1 . Generating mechanisms and relation to behaviour. Brain Research, 407, 68-80.

Leung, L. W.-S., Lopes da Silva, F. H., \& Wadman, W. J. (1982). Spectral characteristics of the hippocampal EEG in the freely moving rat. Electroencephalography \& Clinical Neurophysiology, 54, 203-219.

Levy, W. B., Steward, O. (1983). Temporal contiguity requirement for long term potentiation/depression in the hippocampus. Neuroscience, 8, 791-797.

Lissax, K., \& Grastyan, E. (1960). The changes of hippocampal electrical activity during conditioning. Electroencephalography \& Clinical Neurophysiology (Suppl. 13, The Moscow Colloquium on Electroencephalography of Higher Nervous Activity), 271-279.

Macadar, O., Roig, J. A., Monti, J. M., \& Budelli, R. (1970). The functional relationship between septal and hippocampal unit activity and hippocampal theta rhythm. Physiology \& Behavior, 5, 1443-1449.

MARR, D. (1969). A theory of cerebellar cortex. Journal of Physiology, 202, 437-470.

McNaughton, B. L., \& MorRis, R. G. M. (1987). Hippocampal synaptic enhancement and information storage within a distributed memory system. Trends in Neuroscience, 10, 408-415.

Meibach, R. C., SIEGEL, A. (1977). Subicular projections to posterior cingulate cortex in rats. Experimental Neurology, 57, 264-274.

MILlER, R. (1976). Distribution and properties of commissural and other neurons in cat sensorimotor cortex. Journal of Comparative Neurology, 164, 361-373.

MILLER, R. (1981). Meaning and purpose in the intact brain, Oxford, England: Oxford University Press.

MilLER, R. (1987). Representation of brief temporal patterns, Hebbian synapses, and the left-hemisphere dominance for phoneme recognition. Psychobiology, 15, 241-247.

MILLER, R. (1988). Cortico-striatal and cortico-limbic circuits: A two- tiered model of learning and memory functions. In H. J. Markowitsch (Ed.), Information processing by the brain (pp. 177-195). Bern: Hans Huber Press.

Mishkin, M., \&etri, H. L. (1984). Memories and habits: Some implications for the analysis of learning and retention. In L. R. Squires \& N. Butters (Eds.), Neuropsychology of memory (pp. 287-296). New York: Guildford Press.

MirchelL, S. J., \& RANCK, J. B., JR. (1980). Generation of theta thythm in medial entorhinal cortex of freely moving rats. Brain Research, $189,49-66$.

Montoya, C. P., \& Sainsbury, R. S. (1985). The effects of entorhinal cortical lesions on type 1 and type 2 theta. Physiology \& Behavior, $35,121-126$.

Muller, R. U., \& KubIE, J. L. (1987). The effects of changes in the environment on the spatial firing of hippocampal complex-spike cells Journal of Neuroscience, 7, 1951-1969.

MULleR, R. U., KUBIE, J. L., \& RANCK, J. B., JR. (1987). Spatial firing patterns of hippocampal complex-spike cells in a fixed environment Journal of Neuroscience, 7, 1935-1950.

O'KeEFE, J. (1976). Place units in the hippocampus of freely-moving rats. Experimental Neurology, 51, 78-109.

O'KeEFE, J. (1979). A review of hippocampal place cells. Progress in Neurobiology, 13, 419-439.

O'KeEFE, J., CONWAY, D. H. (1978). Hippocampal place units in the freely-moving rat: Why they fire when they fire. Experimental Brain Research, 31, 573-590.

O'Keefe, J., Speakman, A. (1987). Single unit activity in the rat hippocampus during a spatial memory task. Experimental Brain Research, 68, 1-27.

PALM, G. (1980). On associative memory. Biological Cybernetics, 36, 19-31.

PALM, G. (1982). Neural assemblies. Heidelberg: Springer.

PAPEZ, J. W. (1937). A proposed mechanism of emotion. Archives of Neurology \& Psychiatry, 38, 725-743.

Petsche, H., Gogolak, G., Van Zweiten, P. A. (1965). Rhythmicity of septal discharges at various levels of reticular excitation. Electroencephalography \& Clinical Neurophysiology, 19, 25-33.

Petsche, H., StumpF, C., Gogolak, G. (1962). The significance of the rabbit's septum as a relay station between the midbrain and the hippocampus: 1 . Control of hippocampal arousal activity by the septum cells. Electroencephalography \& Clinical Neurophysiology, 14, 202-211.

Pickenhain, L., \& Kuingberg, F. (1967). Hippocampal slow wave activity as a correlate of basic behavioral mechanisms in the rat. Progress in Brain Research, 27, 218-227.

Porter, R., ADEY, W. R., Brown, T. S. (1964). Effects of small hippocampal lesions on locally recorded potentials and on behavioral performance in the cat. Experimental Neurology, 10, 216-235.

Pribram, K. H. (1986). The hippocampal system and recombinant processing. In R. I. Isaacson \& K. H. Pribram (Eds.), The hippocampus (Vol. 4, pp. 329-370). New York: Plenum.

RadulovackI, M., \& ADEY, W. R. (1965). The hippocampus and the orienting reflex. Experimental Neurology, 12, 68-83.

RALL, W. (1962). Electrophysiology of a dendritic neuron model. Biophysical Journal, 2(2), 145-167.

Remahl, S., \& Hildebrand, C. (1982). Changing relation between onset of myelination and axon diameter in developing feline white matter. Journal of Neurological Science, 54, 33-45.

Rosene, D. L., \& VAN Hoesen, G. W. (1977). Hippocampal efferents reach widespread areas of cerebral cortex and amygdala in the rhesus monkey. Science, 198, 315-317.

ROUTTENBERG, A. (1968). Hippocampal correlates of consummatory and observed behavior. Physiology \& Behavior, 3, 533-535.

SCHWARTZBaum, J. S. (1975). Interrelationships among multiunit activity of the midbrain reticular formation and lateral geniculate nucleus, thalamocortical arousal and behavior in rats. Journal of Comparative Physiological Psychology, 89, 131-157.

SCHWERTFEGER, W. K. (1979). Direct efferent and afferent connections of the hippocampus with the neocortex in the marmoset monkey. American Journal of Anatomy, 156, 77-82. 
Scoville, W. B., Milner, B. (1957). Loss of recent memory after bilateral hippocampal lesions. Journal of Neurology, Neurosurgery \& Psychiatry, 20, 11-21.

SMith, S. J. (1987). Progress on LTP at hippocampal synapses: A postsynaptic $\mathrm{Ca}^{2+}$ trigger for memory storage. Trends in Neuroscience, 10, $142-146$.

STENT, G. S. (1973). A physiological mechanism for Hebb's postulate of learning. Proceedings of the National Academy of Sciences of the United States of America, 70, 997-1001.

Sutherland, N. S., \& MacKintosh, N. J. (1971). Mechanisms of animal discrimination learning. New York: Academic Press.

Swadlow, H. A. (1974). Properties of antidromically activated callosal neurons and neurons responsive to callosal input in rabbit binocular cortex. Experimental Neurology, 43, 424-444.

Thatcher, R. W., Krause, P. J., \& Hrybye, M. (1986). Corticocortical associations and EEG coherence: A two compartment model. Electroencephalography \& Clinical Neurophysiology, 64, 123-143.

VANDERWOLF, C. H. (1969). Hippocampal electrical activity and voluntary movement in the rat. Electroencephalography \& Clinical Neurophysiology, 26, 407-418.

VANDERWOLF, C. H. (1975). Neocortical and hippocampal activation in relation to behavior: Effects of atropine, eserine, phenothiazine and amphetamine. Journal of Comparative \& Physiological Psychology, 88, 300-323.

Vanderwolf, C. H., Kramis, R., \& Robinson, T. E. (1978). Hippocampal electrical activity during waking behaviour and sleep: Analyses using centrally acting drugs. In Functions of the septo-hippocampal system (CIBA Foundation Symposium No. 58, pp. 199-221). Amsterdam: Elsevier North-Holland.

VANDERWOLF, C. H., \& LEUNG, L. W.-S. (1983). Hippocampal rhythmic slow activity: A brief history and effects of entorhinal lesions and phencyclidine. In W. Seifert (Ed.), Neurobiology of the hippocampus (pp. 275-302). London: Academic Press.

Vanderwolf, C. H., Leung, L. W.-S., \& Cooley, R. K. (1985). Pathways through cingulate, neo- and entorhinal cortices mediate atropine-resistant hippocampal thythmic slow activity. Brain Research, 347, 58-73.

Van Hoesen, G. W., \& Pandya, D. N. (1975a). Some connections of the entorhinal (area 28) and perishinal (area 35) cortices of the thesus monkey: II. Frontal lobe afferents. Brain Research, 95, 25-38.

Van Hoesen, G. W., \& Pandya, D. N. (1975b). Some connections of the entorhinal (area 28) and perirtinal (area 35) cortices of the rhesus monkey: III. Efferent connections. Brain Research, 95, 39-59.

Van Hoesen, G. W., Pandya, D. N., \& Butters, N. (1972). Cortical afferents to the entorhinal cortex of the rhesus monkey. Science, $175,1471-1473$

VERTES, R. P. (1981). An analysis of ascending brainstem systems involved in hippocampal synchronization and desynchronization. Journal of Neurophysiology, 24, 907-935.

Vinogradova, O. S., \& BrazNiK, E. S. (1978). Neuronal aspects of septo-hippocampal relations. In Functions of the septo-hippocampal system (CIBA Foundation Symposium, No. 58, pp. 145-177). Amsterdam: Elsevier North-Holland.

Vinogradova, O. S., Braznik, E. S., Karanov, A. M., Zhadina, S. D. (1980). Neuronal activity of the septum following various types of deafferentation. Brain Research, 187, 353-368.
Walter, D. O., \& ADEY, W. R. (1963). Spectral analysis of electroencephalograms during learning in the cat, before and after subthalamic lesions. Experimental Neurology, 7, 481-503.

Waxman, S. G., \& SWADLow, H. A. (1976). Ultrastructure of visual callosal axons in the rabbit. Experimental Neurology, 53, 115-127.

Whishaw, I. Q., \& VANDERWolf, C. H. (1973). Hippocampal EEG and behavior: Changes in amplitude and frequency of RSA (theta rhythm) associated with spontaneous and learned movement patterns in rats and cats. Physiology and Behavior, 6, 391.

WiCKENS, J. R. (1988). Electrically coupled but chemically isolated synapses: Dendritic spines and calcium in a rule for synaptic modification. Progress in Neurobiology, 31, 507-528.

Wigström, H., \& Gustafsson, B. (1985). On long-lasting potentiation in the hippocampus: A proposed mechanism for its dependence on coincident pre- and post-synaptic activity. Acta Physiologica Scandinavica, 123, 519-522.

Winson, J. (1974). Patterns of hippocampal theta rhythm in the freely moving rat. Electroencephalography \& Clinical Neurophysiology, 36, 291-301.

Winson, J. (1976). Hippocampal theta rhythm: II. Depth profiles in the freely moving rabbit. Brain Research, 103, 71-79.

Winson, J. (1978). Loss of hippocampal theta rhythm results in spatial memory deficit in the rat. Science, 201, 160-162.

YERKES, R. M., DoDson, J. D. (1908). The relation between strength of stimulus and rapidity of habit formation. Journal of Comparative Neurology, 18, 459-482.

\section{APPENDIX}

Reference should also be made to a theoretical paper (Leung, 1984a) that is helpful for anyone who wishes to understand phase profiles, but that nonetheless contains a serious source of confusion. It is shown in this paper that a plausible simulation of the observed gradual phase shift between superficial and deep laminae of CA1 would consist of two theta-modulated synaptic inputs to the CAl pyramidal cells, one directed at stratum pyramidale, the other directed at the distal dendrites in stratum lacunosum/moleculare, these two being out of phase by $45^{\circ}$. The point of confusion, whose clarification is crucial for the functional interpretation presented here, is as follows: Leung (1984a, Figure 3) assumes that the superficial input is an IPSP, the deep one an EPSP. The peak of hyperpolarization in the superficial layers of CA1 thus lags the peak depolarization in the deep layers by the stated value of $45^{\circ}$. This would be equivalent to a $225^{\circ}$ lead of the deep potentials, or a $135^{\circ}$ phase lag. This is a phase shift in the direction opposite to the experimental results. However, other possible arrangements of synaptic input should be considered. For instance, if it is assumed that a superficial EPSP leads a deep IPSP by $45^{\circ}$, then Leung's computations would give potentials similar to those found experimentally.

(Manuscript received June 27, 1988; revision accepted for publication December $12,1988$. ) 